\title{
Dietary Adherence, Self-Regulatory Fatigue and Trait Self-Control Among Chinese Patients with Peritoneal Dialysis: A Cross-Sectional Study
}

This article was published in the following Dove Press journal: Patient Preference and Adherence

\author{
Yajing Gao' \\ Yan Shan ${ }^{2}$ \\ Tingting Jiang ${ }^{3}$ \\ $\mathrm{Li} \mathrm{Cai}{ }^{4}$ \\ Fanliang Zhang ${ }^{3}$ \\ Xinxin Jiang' \\ Xue $\mathrm{Li}^{1}$ \\ Hong Wang' \\ 'Nursing and Health School of \\ Zhengzhou University, Zhengzhou, \\ Henan, People's Republic of China; \\ ${ }^{2}$ Medical School of Zhengzhou University, \\ Zhengzhou, Henan, People's Republic of \\ China; ${ }^{3}$ Zhengzhou University First \\ Affiliated Hospital, Zhengzhou, Henan, \\ People's Republic of China; ${ }^{4}$ Renji \\ Hospital Affiliated to Shanghai Jiao Tong \\ University, Shangai, People's Republic of \\ China
}

Purpose: Little is known about factors that predict dietary adherence among Chinese patients undergoing peritoneal dialysis. We investigated whether self-regulatory fatigue and trait self-control influence dietary adherence among Chinese patients with peritoneal dialysis. Methods: A total of 192 Chinese patients undergoing peritoneal dialysis were recruited at two peritoneal dialysis centers. The dietary adherence, trait self-control and self-regulatory fatigue of these patients were assessed using self-administered questionnaires. Clinical data were extracted from the hospital medical records. The significance of several social demographic factors on dietary adherence was analyzed using One-way ANOVA was used to analyze, whereas the association between dietary adherence and self-regulatory fatigue as well as trait self-control were analyzed using Pearson correlation. The independence association between dietary adherence and other influencing factors was assessed using Multivariable linear regression analyses.

Results: We found that peritoneal dialysis patients only moderately adhere to dietary prescriptions. The top three least adherences were observed for salt intake $(1.89 \pm 0.36)$, face of difficulty $(2.86 \pm 0.26)$ and fluid restriction adherence intake $(2.97 \pm 0.30)$. Multivariable linear regression analysis revealed that education level $(\beta=0.339, \mathrm{P}<0.001)$, residence $(\beta=-0.151, \mathrm{P}=0.015)$, self-regulatory fatigue $(\beta=-0.648, \mathrm{P}<0.001)$, and trait selfcontrol $(\beta=0.118, \mathrm{P}=0.022)$ were independent predictors of dietary adherence.

Conclusion: Education level and residence strongly influence dietary adherence among Chinese peritoneal dialysis patients. On the other hand, Self-regulatory fatigue and trait selfcontrol are independent predictors of dietary adherence among peritoneal dialysis patients. These findings can guide the enhancement of dietary adherence of peritoneal dialysis patients.

Keywords: peritoneal dialysis, dietary adherence, trait self-control, self-regulatory fatigue

\section{Introduction}

Chronic kidney disease (CKD) is a major public health problem. The increase in the incidence rate of $\mathrm{CKD}$ is driven by a global rise in the aging population and the parallel increased in the prevalence of diabetes and hypertension. ${ }^{1}$ If not well treated and managed, CKD progresses to end-stage renal disease (ESRD), where the affected patients rely on renal replacement therapy (RRT) to maintain normal physiological function. The number of patients receiving RRT (dialysis or renal transplantation) is predicted to more than double by $2030 .^{2}$ Compared with hemodialysis and renal transplantation, peritoneal dialysis offers superior survival
Correspondence: Yan Shan Email sylI0@sina.com 
advantages, and markedly improves the quality of life of patients during the early years of the therapy. ${ }^{3-5}$ There are more than 272000 peritoneal dialysis patients worldwide, representing approximately $11 \%$ of the dialysis population. Besides these bleak statistics, the incidence of CKD is estimated to increase by $8 \%$ annually. ${ }^{6}$ In China, the rapid expansion in the use of peritoneal dialysis is billed to offer positive health outcomes and socioeconomic benefits. ${ }^{7}$ The Chinese government and health care professionals have implemented numerous supportive policies and peritoneal dialysis programs to up-scale the service. ${ }^{8}$ Besides China having the largest numbers of peritoneal dialysis patients in the world, the number of patients in need to physiological support is ever increasing. ${ }^{9}$ The implementation of the shared decisionmaking (SDM) model has further increased the uptake of peritoneal dialysis. ${ }^{10}$

Peritoneal dialysis is a long-term therapy performed several times a day after every 4-5 hours or approximately 8-10 hours at night with the help of a bedside machine. Since peritoneal dialysis is undertaken at home, it calls for strict and multifaceted self-management discipline, including dialysis regime management, diet and fluid intake restrictions and self-monitoring of any arising complication. However, adherence and persistence cannot be guaranteed due to the heavy self-care burden. Besides, psychosocial issues such as anxiety and social isolation may cause physical and physiological burnout among patients, thus affecting adherence. ${ }^{11,12}$ Previous surveys have reported that age, belief, depression and selfefficacy influence adherence to peritoneal dialysis restrictions. ${ }^{13,14}$ Non-adherence to diet and fluids is one of the major problems among peritoneal dialysis patients. Research shows that the non-adherence rate of peritoneal dialysis patients to diet is as high as $67 \% .{ }^{15}$ Poor dietary adherence induces fluid overload, interdialytic weight gain and hypertension, all of which worsen the prognosis of the kidney complications. ${ }^{16,17}$

Peritoneal dialysis patients require consistent adherence to sodium, potassium and protein intake limits, which affects their well-being and their social interactions. Thus, peritoneal dialysis patients intentionally or unintentionally flout dietary restrictions as a result of emotional hunger or impulse craving. ${ }^{14}$

Based on the self-control and strength model, the capacity of people to restrain themselves is limited, occasioned by prolonged self-control. ${ }^{18}$ Recently, researches revealed that far too long-term demand of self-control may impair individual self-control capacity on dietary intake behavior. ${ }^{19,20}$ Although trait self-control, self-regulatory fatigue and dietary adherence among peritoneal dialysis patients seem to be interlinked, the potential association among these factors has only been scarcely reported. Besides, current interventions to promote dietary adherence in peritoneal dialysis patients have focused on activating instead of maintaining dietary adherence behaviors. ${ }^{21}$ Consequently, researches are needed to unearth factors that can promote and maintain dietary adherence among peritoneal dialysis patients. Against this background, we sought to (1) describe the current status of dietary adherence and its influencing factors among Chinese patients with peritoneal dialysis and (2) examine the association between dietary adherence with self-regulatory fatigue and trait self-control.

\section{Methods}

\section{Study Design}

A cross-sectional study was conducted in Zhengzhou City, Henan Province, China between June 2020 and November 2020. This study was approved by the Ethics Committee of Zhengzhou University. All participants signed written informed consent. This study was conducted in accordance with the declaration of Helsinki.

\section{Participants}

Patients were recruited from two peritoneal dialysis centers. The inclusion criteria for the peritoneal dialysis patients were 18 years old or above, ability to communicate and willing to participate in the study. Patients who were not on peritoneal dialysis and suffered severe mental or cognitive disease were excluded.

Research assistants approached and explained to the eligible patients the purpose of the study. Patients that consented to participate underwent a face-to-face interview in a private room at the hospital.

\section{Measured Variables \\ Demographic Characteristics}

The socio-demographic data of patients captured included age, gender, educational level, health insurance and average household income. Clinical data included duration of peritoneal dialysis, presence of other chronic diseases, level of serum albumin, frequency of nutrition referral and nutritional status. 


\section{Dietary Adherence}

Dietary adherence behavior was measured using the renal adherence behavior questionnaire (RABQ). ${ }^{22}$ The RABQ comprises of 25 items that assess five parameters; fluid, salt and potassium intake adherence, self-care adherence and restrain in face of conflict. Each item was scored on a scale of 1 to 5, with higher scores indicative of greater levels of adherence.

\section{Self-Regulatory Fatigue}

The levels of chronic self-regulatory depletion was evaluated using the self-regulatory fatigue scale (SRF-S), developed by Nes et $\mathrm{al}^{23}$ and translated to Chinese by Ligang Wang et al. ${ }^{24}$ The reliability and validity of the scale to measure chronic multi-symptom illnesses have been previously demonstrated. ${ }^{25}$ The SRF-S comprises 16 items and assesses 3 domains; cognition, emotion and behavior. The items were scored on a scale of 1 to 5 , with the score being directly proportional to the level of self-regulatory deception.

\section{Trait Self-Control}

The trait self-control was assessed using the Trait Selfcontrol Scale (TSCS). This scale comprises twenty-five items and five subscales; concentration on work, practicing of healthy habits, rational behavior, restrain to impulses and resistance to temptation. Participants scored each item on a 1-5-point Likert scale based on how well they assessed themselves. The higher the score, the higher the level of trait self-control.

\section{Statistical Analyses}

The participants' characteristics were first summarized using frequency distributions and thereafter analyzed using descriptive statistics. Differences between groups were analyzed using one way-ANOVA, whereas the relationship between continuous dependent and independent variables was evaluated using bivariate Pearson correlation analyses. The association between self-regulatory fatigue and self-control with dietary adherence was evaluated using multiple linear regression analyses. The data was analyzed using SPSS V.23.0, with statistical significance set at $P<0.05$.

\section{Ethics}

The study was approved by the Ethics Committee of Zhengzhou University. All participants signed written informed consent.

\section{Results}

\section{Demographic Variables}

Only $192(92.3 \%)$ of the 208 peritoneal patients participated the survey. Eight of the 16 patients who declined to participate in the study doubted the benefits of this research. Also, two patients dropped due to health issues, four patients explained their non-response due to examination and treatment whereas two patients felt the research was time consuming.

The participants ranged between 22 and 66 years old, with a mean age of 44.30 years and standard deviation (SD) of 10.01years. The majority of the participants were between 46 and 49 years old. Of the 192, 95 (49.5\%) were males whereas 97 (50.5\%) were females. In addition, the majority of the participants (59.4\%) were unemployed and married 168 (87.5\%). In addition, $40.1 \%$ and $35.4 \%$ of the participants were respectively of primary school and middle school education levels. Moreover, $52.6 \%$ of the participants resided in the rural areas. Finally, the majority of the patients $(35.9 \%)$ had received peritoneal dialysis for between 12 and 24 months. The above findings are summarized in Table 1.

\section{The Association Between Demographic Variables and Dietary Adherence}

Age, education level, household income and residential location strongly influenced adherence to diet. For instance, compared with younger patients, older patients were less likely to adhere to dietary guidelines. On the other hand, the level of education was directly proportional to dietary adherence. Moreover, patients in the rural areas were more likely to flout dietary restrictions as compared to their urbandwelling counterparts. Finally, economic status was directly proportional to dietary adherence.

\section{The Dietary Adherence, Self-Regulatory Fatigue and Trait Self-Control Levels of Peritoneal Dialysis Patients}

The mean dietary adherence score was $71.57 \pm 3.32$. The least adherence was observed for salt intake $(1.89 \pm 0.36)$, restrain in the face of conflict $(2.86 \pm 0.26)$ and fluid intake recommendations $(2.97 \pm 0.30)$. The mean SRF-S score was $41.56 \pm 4.30$, whereas emotional control was the best observed domain $(3.09 \pm 0.36)$ 
Table I The Association Between Dietary Adherence and the Socio-Demographics as Well as Patient-Related Factors ( $\mathrm{N}=192)$

\begin{tabular}{|c|c|c|c|c|c|}
\hline Variables & $\mathbf{N}(\%)$ & Dietary Adherence Score Mean & Std. Deviation & F-value & $P$-value \\
\hline Age & & & & 8.499 & $<0.001$ \\
\hline $18 \sim 30$ & $18(9.4)$ & 72.94 & 3.44 & & \\
\hline $31 \sim 45$ & $66(34.4)$ & 72.68 & 3.08 & & \\
\hline $46 \sim 59$ & $97(50.5)$ & 70.88 & 3.12 & & \\
\hline$>60$ & II (5.7) & 68.73 & 3.13 & & \\
\hline Education level & & & & 51.844 & $<0.001$ \\
\hline Primary school or lower & $27(14.1)$ & 66.81 & 2.00 & & \\
\hline Middle school & $77(40.1)$ & 71.16 & 2.58 & & \\
\hline High school & $68(35.4)$ & 73.03 & 2.53 & & \\
\hline Junior college or higher & $20(10.4)$ & 74.60 & 2.44 & & \\
\hline Household income & & & & 18.957 & $<0.001$ \\
\hline$<1000$ & $6(3.1)$ & 67.33 & 2.34 & & \\
\hline $1000 \sim$ & $91(47.4)$ & 70.33 & 2.91 & & \\
\hline $3000 \sim$ & $80(4 I .7)$ & 72.74 & 3.17 & & \\
\hline$\geq 5000$ & $15(7.8)$ & 74.53 & 1.55 & & \\
\hline Marital status & & & & -2.303 & 0.022 \\
\hline Single or other & $24(12.5)$ & 70.13 & 4.13 & & \\
\hline Married & $168(87.5)$ & 71.77 & 3.15 & & \\
\hline Employment status & & & & 3.255 & 0.001 \\
\hline Employed & $78(40.6)$ & 72.49 & 3.03 & & \\
\hline Unemployed & $114(59.4)$ & 70.94 & 3.37 & & \\
\hline Residence & & & & 8.844 & $<0.001$ \\
\hline Urban area & 91 (47.4) & 73.45 & 2.77 & & \\
\hline Rural area & $101(52.6)$ & 69.97 & 2.83 & & \\
\hline Duration of peritoneal dialysis & & & & 2.024 & 0.112 \\
\hline$<6$ months & $16(8.3)$ & 72.56 & 2.87 & & \\
\hline $6 \sim 12$ months & $63(32.8)$ & 72.14 & 3.32 & & \\
\hline I2 24 months & $69(35.9)$ & 71.28 & 3.19 & & \\
\hline Nutritional status & & & & 0.337 & 0.714 \\
\hline Good & $42(21.9)$ & 71.81 & 3.56 & & \\
\hline Mild to moderate malnutrition & $144(75.0)$ & 71.53 & 3.27 & & \\
\hline Severe malnutrition & $6(3.1)$ & 70.67 & 3.20 & & \\
\hline
\end{tabular}

(Continued) 
Table I (Continued).

\begin{tabular}{|l|l|l|l|c|c|}
\hline Variables & N (\%) & Dietary Adherence Score Mean & Std. Deviation & F-value & $P$-value \\
\hline Frequency of nutrition referral & & & & 1.317 & 0.270 \\
\hline Every month & $18(9.4)$ & 70.28 & 2.70 & \\
\hline Every I to 3 months & $159(82.8)$ & 71.77 & 3.43 & \\
\hline Every 3 to 6 months & $11(5.7)$ & 70.82 & 2.68 & \\
\hline More than 6 months & $4(2.1)$ & 71.25 & 1.26 & \\
\hline Serum albumin level & 33.33 & 4.23 & & \\
\hline
\end{tabular}

Table 2 The Measure of Dietary Adherences, Self-Regulatory Fatigue and Trait Self-Control

\begin{tabular}{|l|l|l|}
\hline Variable & Scores & Item Average Scores \\
\hline Summary of dietary adherence & $71.57 \pm 3.32$ & \\
\hline Fluid restriction adherence & $32.63 \pm 2.06$ & $2.97 \pm 0.30$ \\
\hline Adherence to potassium intake & $15.61 \pm 1.47$ & $3.12 \pm 0.41$ \\
\hline Self-care adherence & $6.49 \pm 0.89$ & $3.25 \pm 0.45$ \\
\hline Restrain in face of conflict & $14.34 \pm 1.32$ & $2.86 \pm 0.26$ \\
\hline Adherence to salt intake & $3.77 \pm 0.71$ & $1.89 \pm 0.36$ \\
\hline Summary of self-regulatory fatigue & $41.56 \pm 4.30$ & \\
\hline Cognitive control & $13.21 \pm 2.52$ & $2.20 \pm 0.42$ \\
\hline Behavioral control & $13.54 \pm 2.30$ & $2.70 \pm 0.46$ \\
\hline Emotional control & $15.47 \pm 1.81$ & $3.09 \pm 0.36$ \\
\hline Summary of trait self-control & $72.81 \pm 6.07$ & \\
\hline Concentration on work & $17.80 \pm 1.39$ & $2.54 \pm 0.20$ \\
\hline Observing healthy habits & $12.72 \pm 1.19$ & $3.18 \pm 0.30$ \\
\hline Behavioral rationality & $12.29 \pm 1.44$ & $3.07 \pm 0.36$ \\
\hline Overcoming impulses & $17.85 \pm 1.85$ & $2.98 \pm 0.31$ \\
\hline Resisting temptation & $12.43 \pm 1.50$ & $3.11 \pm 0.38$ \\
\hline
\end{tabular}

The mean TSCS score was $72.81 \pm 6.07$. These findings are summarized in Table 2.

\section{Association Between Dietary Adherence, Trait Self-Control and Self-Regulatory Fatigue}

Pearson correlation coefficient analysis revealed that self-regulatory fatigue was negatively associated with dietary adherence $(\mathrm{r}=-0.632, \mathrm{P}<0.001)$, with behavioral control being the most significant variable $(\mathrm{r}=-0.454$, $\mathrm{P}<0.001$ ) (Table 3). In contrary, trait self-control and dietary adherence displayed a relatively strong positive correlation $(\mathrm{r}=0.354, \mathrm{P}<0.001)$. Also, resistance to temptation displayed the strongest positive association with self-regulatory fatigue $(r=0.447, \mathrm{P}<0.001)$. These findings are summarized in Table 4. 
Table 3 Pearson Correlation Coefficients Between Dietary Adherence and Self-Regulatory Fatigue

\begin{tabular}{|l|l|l|l|l|}
\hline Variables & Self-Regulatory Fatigue & Cognitive Control & Behavioral Control & Emotional Control \\
\hline Dietary adherence & $-0.632^{* *}$ & $-0.287^{* *}$ & $-0.454^{* *}$ & $-0.31 I^{* *}$ \\
\hline Fluid restriction adherence & $-0.269^{* *}$ & -0.136 & $-0.212^{* *}$ & $-0.145^{* *}$ \\
\hline Adherence to potassium intake & $-0.183^{* *}$ & 0.039 & $0.199^{* *}$ & $0.240^{* *}$ \\
\hline Self-care adherence & -0.038 & 0.124 & -0.083 & -0.069 \\
\hline Restrain in the face of conflict & -0.034 & -0.028 & -0.080 & 0.016 \\
\hline Adherence to salt intake & 0.024 & -0.042 & 0.048 & 0.053 \\
\hline
\end{tabular}

Notes: **Indicates $\mathrm{P}<0.01$. Two-tailed significance.

Table 4 Pearson Correlation Coefficients Between Dietary Adherence and Trait Self-Control

\begin{tabular}{|l|l|l|l|l|l|l|}
\hline Variables & $\begin{array}{l}\text { Trait Self- } \\
\text { Control }\end{array}$ & $\begin{array}{l}\text { Concentration to } \\
\text { Work }\end{array}$ & $\begin{array}{l}\text { Observing Healthy } \\
\text { Habits }\end{array}$ & $\begin{array}{l}\text { Rational } \\
\text { Behavior }\end{array}$ & $\begin{array}{l}\text { Resisting } \\
\text { Impulses }\end{array}$ & $\begin{array}{l}\text { Resisting } \\
\text { Temptation }\end{array}$ \\
\hline Dietary adherence & $0.354^{* *}$ & 0.119 & 0.101 & $0.219 * *$ & $0.311^{* *}$ & $0.447^{* *}$ \\
\hline $\begin{array}{l}\text { Fluid restriction } \\
\text { adherence }\end{array}$ & 0.003 & 0.001 & 0.069 & -0.013 & -0.018 & 0.024 \\
\hline $\begin{array}{l}\text { Adherence to } \\
\text { potassium intake }\end{array}$ & $0.240 * *$ & 0.039 & $0.199 * *$ & $0.240 * *$ & 0.055 & $0.273^{* *}$ \\
\hline Self-care adherence & 0.038 & -0.027 & -0.025 & -0.106 & 0.093 & 0.080 \\
\hline $\begin{array}{l}\text { Refrain in the face of } \\
\text { conflict }\end{array}$ & 0.030 & 0.017 & -0.076 & -0.033 & 0.092 & $0.179 *$ \\
\hline $\begin{array}{l}\text { Adherence to salt } \\
\text { intake }\end{array}$ & -0.047 & 0.102 & -0.126 & 0.087 & -0.023 & 0.091 \\
\hline
\end{tabular}

Notes: *Significant at $\mathrm{P}<0.05$, **significant at $\mathrm{P}<0.01$, two-tailed test.

\section{Predictive Factors for Dietary Adherence}

Multiple linear regression analysis for factors associated with dietary adherence of peritoneal dialysis patients are shown in Table 5.

\section{Discussion}

This study assessed the association between self-regulatory fatigue, trait self-control and dietary adherence among Chinese peritoneal dialysis patients. Patients with higher self-regulatory fatigue or poor trait self-control were less likely to adhere to diet restrictions. Higher level of Education and urban dwelling were associated with better dietary adherence of Chinese peritoneal dialysis patients.

Self-regulatory fatigue was a strong predictor of dietary adherence, consistent with previous findings, in which selfregulatory fatigue was associated with low adherence to healthy behaviors among patients with hematologic malignancies. ${ }^{26}$ Moreover, self-regulatory depletion or fatigue causes self-regulatory fatigue. ${ }^{27}$ Meanwhile, emotional control had the greatest influence on patients' self-regulatory fatigue. It has been reported that Dohsa-hou psychotherapy promotes self-regulatory management in hemodialysis patients. ${ }^{28}$ Consequently, similar psycho-rehabilitative activities may greatly improve dietary adherence of peritoneal dialysis patients. In addition, self-control strongly predicts the likelihood of dietary adherence. Trait self-control is a dispositional capacity that plays an important role in activities that demand self-restrain. ${ }^{29}$ Research shows that patients with high trait self-control have a superior capacity to sustain health-related behavior. ${ }^{30}$ This study also found that resistance to temptation and impulses significantly impact on dietary adherence, consistent with a previous findings, in which patients with low trait self-control found it difficult to resist eat unhealthy food. ${ }^{31}$ This underlines the role of self-control in clinical management of peritoneal dialysis. Although trait selfcontrol behavior cannot be easily changed, it can be improved 
Table 5 Factors Associated with Dietary Adherence Behavior

\begin{tabular}{|l|c|c|c|c|c|c|}
\hline \multirow{2}{*}{ Independent Variables } & \multicolumn{2}{|c|}{$\begin{array}{c}\text { Unstandardized } \\
\text { Coefficient }\end{array}$} & Standardized Coefficient & $\mathbf{t}$ & P-value & 95\% Confidence Interval for B \\
\cline { 2 - 7 } & $\mathbf{B}$ & $\mathbf{S E}$ & \multicolumn{2}{|c|}{$\boldsymbol{\beta}$} & & \\
\hline Constant & 77.043 & 3.064 & & 25.15 & $<0.001$ & $71.00,83.08$ \\
\hline Educational level & 1.311 & 0.247 & 0.339 & 5.31 & $<0.001$ & $0.82,1.80$ \\
\hline Residence & -1.004 & 0.408 & -0.151 & -2.46 & 0.015 & $-1.81,-0.20$ \\
\hline Self-regulatory fatigue & -0.284 & 0.044 & -0.648 & -6.48 & $<0.001$ & $-0.37,-0.20$ \\
\hline Trait self-control & 0.064 & 0.028 & 0.118 & 2.31 & 0.022 & $0.01,0.12$ \\
\hline F & 62.84 & & & & & \\
\hline$R^{2}$ & $0.56 \%$ & & & & & \\
\hline
\end{tabular}

Abbreviations: $B$, unstandardized coefficient; SE, standard error; $\beta$, standardized coefficient.

through training, including repeated self-affirmation. ${ }^{32,33}$ Notably, trait self-control was negatively associated with selfregulatory fatigue. Indeed, previous studies have demonstrated that trait self-control is a key self-regulatory resource, ${ }^{34}$ in line with the self-control and strength model.

However, we found no significant association between the duration of peritoneal dialysis and patients' dietary adherence. Previous studies have reported comparable findings. ${ }^{35,36}$ Even so, healthcare professionals pay more attention to patients newly receiving peritoneal dialysis. ${ }^{37}$ However, prolonged attention may induce non-adherence attitude and behavior. Thus, the level of dietary adherence may be influenced by the duration of treatment. However, given that this study only assessed the current status and short-term behavior of peritoneal dialysis patients, longterm researches should be conducted to fully dissect behavioral changes among peritoneal dialysis patients. Even so, healthcare workers remain the current focal points in guiding monitoring dietary adherence. ${ }^{38}$

In addition, urban dwellers and welllearned individuals were more likely to observe dietary restrictions, consistent with previous findings. ${ }^{39}$ Given the significance of knowledge on dietary adherence, healthcare professionals should upscale teaching sessions on healthy eating among peritoneal dialysis patients. ${ }^{40}$ Indeed, solution-focused communication by health professionals substantially improving patient adherence to health-care demands. ${ }^{41,42}$ Thus, healthcare professionals caring for peritoneal dialysis patients require specialized training on the significance of solution-focused education in this group of patients Previous research among Chinese population revealed that patients in the rural areas were less likely to adhere to oral anticoagulation supplements, ${ }^{43}$ comparable with our findings with regard to dietary adherence. This may in part be attributed to the distribution of Chinese peritoneal dialysis centers between the two settings. Specifically, because the majority of rural peritoneal dialysis patients live far from peritoneal dialysis units, they are constrained with limited access and readily available support on peritoneal dialysis. ${ }^{44}$ In addition, rural patients are likely to be ignorant of peritoneal dialysis knowledge, confounded by less income to afford the recommended foods. Therefore, stakeholders should pay particular attention to rural peritoneal dialysis patients. Strategies such as remote monitoring and text messaging can enhance patient-focused care and outcomes for this group of patients. ${ }^{45,46}$ Besides these, the government should accelerate the up-scaling of peritoneal dialysis units to the rural areas.

Regarding limitations, first, the credibility of the data may be questionable, given the self-reporting nature of parameters of interest. Second, because we only analyzed data for patients in two centers, the findings may not be representative. Finally, several other variables associated with dietary adherence among peritoneal dialysis patients were not examined. Therefore, future studies should focus on experience and trend on dietary adherence following prolonged peritoneal dialysis.

\section{Conclusion}

Summarily, several factors influence dietary adherence among Chinese peritoneal dialysis patients. However, the self-control and strength model provides a framework for 
relevant interventions than can improve dietary adherence among peritoneal dialysis patients.

\section{Author Contributions}

All authors made substantial contributions to conception and design, acquisition of data, or analysis and interpretation of data; took part in drafting the article or revising it critically for important intellectual content; agreed to submit to the current journal; gave final approval of the version to be published; and agree to be accountable for all the work.

\section{Disclosure}

The authors declare no conflicts of interest in this work.

\section{References}

1. Hill NR, Fatoba ST, Oke JL, et al. Global prevalence of chronic kidney disease - a systematic review and meta-analysis. PLoS One. 2016;11(7):e0158765. doi:10.1371/journal.pone.0158765

2. Liyanage $T$, Ninomiya $T$, Jha $V$, et al. Worldwide access to treatment for end-stage kidney disease: a systematic review. Lancet. 2015;385 (9981):1975-1982. doi:10.1016/S0140-6736(14)61601-9

3. Machowska A, Rutherford P. Peritoneal dialysis use within the context of the population and healthcare systems of Europe - differences, trends and future challenges. Int J Artif Organs. 2016;39(5):211-219. doi:10.5301/ijao.5000499

4. Zazzeroni L, Pasquinelli G, Nanni E, Cremonini V, Rubbi I. Comparison of quality of life in patients undergoing hemodialysis and peritoneal dialysis: a systematic review and meta-analysis. Kidney Blood Press Res. 2017;42(4):717-727. doi:10.1159/000484115

5. Jung HY, Jeon Y, Park Y, et al. Better quality of life of peritoneal dialysis compared to hemodialysis over a two-year period after dialysis initiation. Sci Rep. 2019;9(1):10266. doi:10.1038/s41598-019-46744-1

6. Li PK, Chow KM, Van de Luijtgaarden MW, et al. Changes in the worldwide epidemiology of peritoneal dialysis. Nat Rev Nephrol. 2017;13(2):90-103. doi:10.1038/nrneph.2016.181

7. Yu X, Mehrotra R, Yang X. Components of a successful peritoneal dialysis program. Semin Nephrol. 2017;37(1):10-16. doi:10.1016/j. semnephrol.2016.10.003

8. Yu X, Yang X. Peritoneal dialysis in China: meeting the challenge of chronic kidney failure. Am J Kidney Dis. 2015;65(1):147-151. doi:10.1053/j.ajkd.2014.08.023

9. Wilkie M, Davies S. Insights on Peritoneal Dialysis in China. Perit Dial Int. 2018;38(Suppl 2):S16-s18. doi:10.3747/pdi.2018.00224

10. Lee CT, Cheng CY, Yu TM, et al. Shared decision making increases living kidney transplantation and peritoneal dialysis. Transplant Proc. 2019;51(5):1321-1324. doi:10.1016/j.transproceed.2019.02.025

11. Jacquet $\mathrm{S}$, Trinh $\mathrm{E}$. The potential burden of home dialysis on patients and caregivers: a narrative review. Can J Kidney Health Dis. 2019;6:2054358119893335. doi:10.1177/2054358119893335

12. Fung TKF, Ng YL, Lam MF, Lee KKW. Psychosocial factors predict nonadherence to PD treatment: a Hong Kong survey. Perit Dial Int. 2017;37(3):331-337. doi:10.3747/pdi.2016.00094

13. García-Llana H, Remor E, Selgas R. Adherence to treatment, emotional state and quality of life in patients with end-stage renal disease undergoing dialysis. Psicothema. 2013;25(1):79-86. doi:10.7334/psicothema2012.96

14. Yu ZL, Lee VY, Kang AW, et al. Rates of intentional and unintentional nonadherence to peritoneal dialysis regimes and associated factors. PLoS One. 2016;11(2):e149784. doi:10.1371/journal. pone. 0149784
15. Cameron DW, Griva K, Lai AY, et al. Non-adherence in patients on peritoneal dialysis: a systematic review. PLoS One. 2014;9:2.

16. Flythe JE, Mangione TW, Brunelli SM, Curhan GC. Patient-stated preferences regarding volume-related risk mitigation strategies for hemodialysis. Clin J Am Soc Nephrol. 2014;9(8):1418-1425. doi:10.2215/CJN.03280314

17. Inal S, Erten Y, Tek N, et al. The effect of dietary salt restriction on hypertension in peritoneal dialysis patients. Turk J Med Sci. 2014;44 (5):814-819. doi:10.3906/sag-1308-58

18. Hagger MS, Wood C, Stiff C, Chatzisarantis NL. Ego depletion and the strength model of self-control: a meta-analysis. Psychol Bull. 2010;136(4):495-525. doi:10.1037/a0019486

19. Wang L, Tao T, Fan C, Gao W, Wei C. The influence of chronic ego depletion on goal adherence: an experience sampling study. PLoS One. 2015;10(11):e0142220. doi:10.1371/journal.pone.0142220

20. Hagger MS, Panetta G, Leung CM, et al. Chronic inhibition, selfcontrol and eating behavior: test of a 'resource depletion' model. PLoS One. 2013;8(10):e76888. doi:10.1371/journal.pone.0076888

21. Hare J, Clark-Carter D, Forshaw M. A randomized controlled trial to evaluate the effectiveness of a cognitive behavioural group approach to improve patient adherence to peritoneal dialysis fluid restrictions: a pilot study. Nephrol Dial Transplant. 2013;29(3):555-564. doi:10.1093/ndt/gft477

22. Rushe H, McGee HM. Assessing adherence to dietary recommendations for hemodialysis patients: the Renal Adherence Attitudes Questionnaire (RAAQ) and the Renal Adherence Behaviour Questionnaire (RABQ). J Psychosom Res. 1998;45(2):149-157. doi:10.1016/S0022-3999(97)00228-6

23. Nes LS, Ehlers SL, Whipple MO, Vincent A. Self-regulatory fatigue in chronic multisymptom illnesses: scale development, fatigue, and self-control. J Pain Res. 2013;6:181-188. doi:10.2147/JPR.S40014

24. Wang L, Yu Y, Tao T, Zhang J, Gao W. The self-care dilemma of type 2 diabetic patients: the mechanism of self-regulation resource depletion. PLoS One. 2018;13(12):e0208690.

25. Nes LS, Ehlers SL, Whipple MO, Vincent A. Self-regulatory fatigue: a missing link in understanding fibromyalgia and other chronic multisymptom illnesses. Pain Pract. 2017;17(4):460-469. doi:10.1111/ papr. 12480

26. Solberg Nes L, Ehlers SL, Patten CA, Gastineau DA. Self-regulatory fatigue, quality of life, health behaviors, and coping in patients with hematologic malignancies. Ann Behav Med. 2014;48(3):411-423. doi:10.1007/s12160-014-9621-z

27. Evans DR, Boggero IA, Segerstrom SC. The nature of self-regulatory fatigue and "ego depletion": lessons from physical fatigue. Pers Soc Psychol Rev. 2016;20(4):291-310. doi:10.1177/1088868315597841

28. Haramaki Y, Kabir RS, Abe K, Yoshitake T. Promoting self-regulatory management of chronic pain through dohsa-hou: single-case series of low-functioning hemodialysis patients. Front Psychol. 2019;10. doi:10.3389/fpsyg.2019.01394

29. Hagger MS, Gucciardi DF, Turrell AS, Hamilton K. Self-control and health-related behaviour: the role of implicit self-control, trait self-control, and lay beliefs in self-control. Br J Health Psychol. 2019;24(4):764-786. doi:10.1111/bjhp.12378

30. Hagger MS, Hankonen N, Kangro EM, et al. Trait self-control, social cognition constructs, and intentions: correlational evidence for mediation and moderation effects in diverse health behaviours. Appl Psychol Health Well Being. 2019;11(3):407-437. doi:10.1111/ aphw.12153

31. Gillebaart M, Schneider IK, De Ridder DT. Effects of trait self-control on response conflict about healthy and unhealthy food. J Pers. 2016;84(6):789-798. doi:10.1111/jopy.12219

32. Churchill S, Jessop DC, Green R, Harris PR. Self-affirmation improves self-control over snacking among participants low in eating self-efficacy. Appetite. 2018;123:264-268. doi:10.1016/j. appet.2017.12.028 
33. Friese M, Frankenbach J, Job V, Loschelder DD. Does self-control training improve self-control? A meta-analysis. Perspect Psychol Sci. 2017;12(6):1077-1099. doi:10.1177/1745691617697076

34. Wang Y, Wang L, Cui X, et al. Eating on impulse: implicit attitudes, self-regulatory resources, and trait self-control as determinants of food consumption. Eat Behav. 2015;19:144-149. doi:10.1016/j. eatbeh.2015.09.011

35. Hess LM, Louder A, Winfree K, Zhu YE, Oton AB, Nair R. Factors associated with adherence to and treatment duration of erlotinib among patients with non-small cell lung cancer. J Manag Care Spec Pharm. 2017;23(6):643-652. doi:10.18553/jmcp.2017.16389

36. Arrabal Vela MA, García Gijón CP, Pascual Martin M, et al. Adherence to somatotropin treatment administered with an electronic device. Endocrinol Diabetes Nutr. 2018;65(6):314-318. doi:10.1016/ j.endinu.2018.02.003

37. Wang A, Turnbull L, Williams J, et al. Systematic evaluation of a provincial initiative to improve transition to home dialysis therapies. Can J Kidney Health Dis. 2020;7:2054358120949811. doi:10.1177/2054358120949811

38. Kardasz M, Małyszko J, Stefańska E, Ostrowska L. [Assessment of dietary habits in hemodialysis and peritoneal dialysis patients]. Przegl Lek. 2011;68(4):216-221. Polish.

39. Al-Rasheedi AA. The role of educational level in glycemic control among patients with type II diabetes mellitus. Int J Health Sci (Qassim). 2014;8(2):177-187. doi:10.12816/0006084

40. Schaepe C, Bergjan M. Educational interventions in peritoneal dialysis: a narrative review of the literature. Int J Nurs Stud. 2015;52 (4):882-898. doi:10.1016/j.ijnurstu.2014.12.009
41. Beyebach M, Neipp MDC, García-Moreno M, González-Sánchez I. IMPACT of nurses' solution-focused communication on the fluid adherence of adult patients on haemodialysis. J Adv Nurs. 2018;74 (11):2654-2657. doi:10.1111/jan.13792

42. Gardner AJ, Gray AL, Self S, Wagener JS. Strengthening care teams to improve adherence in cystic fibrosis: a qualitative practice assessment and quality improvement initiative. Patient Prefer Adherence. 2017;11:761-767. doi:10.2147/PPA.S130439

43. Wang X, Xu B, Liang H, et al. Distribution characteristics and factors influencing oral warfarin adherence in patients after heart valve replacement. Patient Prefer Adherence. 2018;12:1641-1648. doi:10.2147/PPA.S172223

44. Wang Z, Zhang Y, Xiong F, et al. Association between medical insurance type and survival in patients undergoing peritoneal dialysis. BMC Nephrol. 2015;16:33. doi:10.1186/s12882-015-0023-7

45. Walker RC, Tong A, Howard K, Palmer SC. Clinicians' experiences with remote patient monitoring in peritoneal dialysis: a semistructured interview study. Perit Dial Int. 2020;40(2):202-208. doi:10.1177/0896860819887638

46. Chen XZ, Yu SJ, Li CY, Zhan XX, Yan WR. Text message-based intervention to improve treatment adherence among rural patients with type 2 diabetes mellitus: a qualitative study. Public Health. 2018;163:46-53. doi:10.1016/j.puhe.2018.06.016
Patient Preference and Adherence

\section{Publish your work in this journal}

Patient Preference and Adherence is an international, peer-reviewed, open access journal that focusing on the growing importance of patient preference and adherence throughout the therapeutic continuum. Patient satisfaction, acceptability, quality of life, compliance, persistence and their role in developing new therapeutic modalities and compounds to optimize clinical outcomes for existing disease

\section{Dovepress}

states are major areas of interest for the journal. This journal has been accepted for indexing on PubMed Central. The manuscript management system is completely online and includes a very quick and fair peer-review system, which is all easy to use. Visit http:// www.dovepress.com/testimonials.php to read real quotes from published authors. 